\title{
Reflexões sobre política linguística e ensino de línguas: configurações de língua(gem) que orientam a formação inicial de professores
}

\author{
Djane Antonucci Correa \\ Universidade Estadual de Ponta Grossa (UEPG), Ponta Grossa, Paraná, Brasil \\ djanecorrea@uol.com.br
}

DOI: http://dx.doi.org/10.21165/el.v46i2.1743

\section{Resumo}

Este trabalho traz um estudo de base qualitativa sobre a compreensão que os professores em formação têm de língua(gem) para subsidiar discussões sobre ensino de língua. Especificamente, busca discutir políticas linguísticas para debater mecanismos que definem o(s) uso(s) da linguagem e verificar que as práticas linguísticas heterogêneas acompanham a evolução sociocultural de todas as línguas do mundo, de modo que os movimentos em direção à homogeneidade são determinados por fatos sociais, políticos e históricos. Os resultados apontam para maior visibilidade às indagações, dificuldades e experiências de professores em formação oriundas de situações sociolinguisticamente complexas, de onde se conclui que as discussões propostas são necessárias para que se compreendam melhor as práticas de linguagem contemporâneas, notadamente diversificadas e multimodais.

Palavras-chave: política linguística; ensino de língua(gem); formação de professores.

Reflections on language policy and language teaching: language settings that guide undergraduate students

\begin{abstract}
This work brings a qualitative study based on the understanding that the undergraduate students have language to support discussions on language teaching. Specifically, it aims to discuss language policies to debate on mechanisms that define use(s) of language and investigate that the heterogeneous linguistic practices accompany the sociocultural evolution of all languages in the world, so the movements toward homogeneity are determined by social, political and historical facts. The results point to greater visibility of questions, difficulties and experiences of teachers in training arising from sociolinguistically complex situations where it is concluded that the proposed discussions are necessary in order to better understand the practices of contemporary language, notably diverse and multi-modal.
\end{abstract}

Keywords: language policy, language teaching, teacher training.

\section{Considerações iniciais sobre língua(gem) e formação do professor}

O princípio deste estudo diz respeito ao ensino de língua e estudos de linguagem. Para delimitar esta ampla abordagem, torna-se muito importante discutir políticas linguísticas mais detidamente, ou seja, as diversas formas nas quais se configuram as práticas linguísticas, a organização, a preservação delas e as implicações dessa compreensão (in)adequada para as práticas de ensino e aprendizagem de língua. 
Desde a publicação dos PCN (1998), e mais recentemente com as discussões sobre a Base Nacional Comum Curricular $(\mathrm{BNCC})^{1}$ junto a pesquisadores e professores formados e em formação, nota-se uma noção de língua muito tênue e flutuante (CORREA, 2009a, 2009b, 2011b, 2014), ou seja, embora muitas vezes se reconheça uma visão heterogênea de língua, os estudos demonstram que, na prática cotidiana (não só pedagógica, mas também social e ideológica), figura-se preponderantemente a visão homogênea, abalizada pela norma padrão, sem considerar as especificidades da norma culta e das variedades linguísticas (FARACO, 2007, 2008).

Por essa razão, este estudo dá continuidade a alguns já realizados anteriormente, de forma mais localizada, (CORREA, 2009a, 2009b, 2011b, 2014) por meio da participação de futuros professores de língua, ou seja, acadêmicas e acadêmicos dos cursos de Licenciatura em Letras ${ }^{2}$. A base da problematização permanece na necessidade de investir esforços na direção de encaminhamentos mais precisos de ensino e aprendizagem de língua, ou seja, mais condizentes com as atuais necessidades e condições sociohistóricas, culturais e econômicas nas quais vivemos. Da mesma forma, abaliza-se nas perdas causadas pela ausência de uma autonomia maior por parte dos professores mediante as descrições de situações sociolinguisticamente complexas e as consequentes aplicações e implicações dessas visões no âmbito didático e pedagógico.

Nesse sentido, considero as discussões acerca das políticas linguísticas (RAJAGOPALAN, 2008, 2009; MAKONI, MEINHOF, 2006; CALVET, 2004, 2007; OLIVEIRA, 2000, 2007, 2009; CORREA, 2009a, 2009b, 2011a; 2011b; 2014) necessárias para que se compreendam melhor algumas configurações de língua(gem) no cenário contemporâneo. Conforme Rajagopalan (2004, p. 135), ao se referir aos estudos realizados dentro das áreas de estudos da linguística e da política linguística,

A primeira sempre fez questão de frisar o caráter descritivo de suas investigações, enquanto que a segunda é escancaradamente prescritiva e interventora. A primeira concentra seus esforços quase exclusivamente no oral, ao passo que a segunda se dirige à escrita, reconhecendo que qualquer repercussão na forma oral da língua ocorre como consequência.

Por sua vez, é inevitável observar, durante os anos de atuação como professora de ensino superior que auxilia na formação de professores de língua materna e estrangeira e também como pesquisadora, a maneira como as crenças e atitudes dos professores formados e em formação vão ganhando novas roupagens, adaptações, mas mantêm, na base, as mesmas contradições. Os episódios recentes em torno da polêmica desencadeada pelo lançamento do livro didático Por uma vida melhor, de Heloísa Ramos, da coleção "Viver, aprender", adotado pelo Programa Nacional do Livro Didático (PNLD) para a Educação de Jovens e Adultos durante o ano de 2011 exemplifica a complexidade do assunto. Para ilustrar o que pode acarretar uma compreensão equivocada de uma proposta, muitos professores, sem nem mesmo ler o conteúdo do livro, procuraram orientações mais qualificadas sobre como proceder, então, diante dos "erros" cometidos pelos alunos. Além do mais, grande parte dos

\footnotetext{
${ }^{1}$ Disponível em: <http://basenacionalcomum.mec.gov.br/\#/site/inicio>. Acesso em: 15 ago. 2016.

2 Professores e professoras que se encontram em formação inicial, a quem registro meus agradecimentos por ajudarem a construir as reflexões aqui apresentadas.
} 
usuários da Língua Portuguesa do Brasil indignou-se com a proposta do livro, entendendo-a como um esforço no sentido de "desqualificar a fala correta", uma opinião reiterada por grande parte de determinados segmentos da mídia.

Por outro lado, associações que representam a área dos estudos de linguagem, tais como ABRALIN e ALAB, além de vários pesquisadores, entre os quais destaco Dante Lucchesi $(2011)^{3}$, manifestaram seus posicionamentos diante de uma questão que poderia ou deveria não ter causado tanta celeuma entre jornalistas, intelectuais de outras áreas do conhecimento e alguns da área do estudo da língua(gem). Além disso, uma parcela significativa das demais pessoas, não especializadas no assunto, quando consultadas ou quando consultavam os credenciados para discutir o tema, diziam, sem pestanejar, que não queriam "falar errado", que não se pode "nivelar por baixo".

Sabemos que o interesse em estudar e dominar as normas que garantem o bem escrever decorre, de maneira direta, da vivência nos centros de pesquisa e também nas salas de aula. É indispensável ao profissional da área de Letras o domínio da norma culta paralelamente à exploração de suas modalidades (CORREA, 2009a, 2009b, 2011a, 2011b).

\section{Políticas linguísticas: objetivos do estudo}

Mantendo o enfoque na continuidade dos estudos sobre políticas linguísticas e as implicações de tais ações para a qualificação do ensino, o objetivo geral deste artigo é apresentar alguns dados de um estudo acerca da indiscutível necessidade de investir esforços na direção de encaminhamentos mais precisos para o ensino e aprendizagem de língua, ou seja, mais condizentes com as atuais necessidades e condições sociohistóricas, culturais e econômicas nas quais vivemos. Para tanto, proponho, a partir de um levantamento sobre a compreensão atual que os professores em formação em Letras, do primeiro ano do curso, na Universidade Estadual de Ponta Grossa, Paraná, têm de língua(gem), registrar e discutir a(s) noção(ões) de língua(gem) adotada(s) atualmente por eles para subsidiar discussões sobre ensino de língua, para que se possa cotejá-las com outros professores em formação inicial.

Os objetivos específicos são: a) discutir políticas linguísticas com os professores participantes e averiguar se tal discussão auxilia os professores a compreender os mecanismos que definem o(s) uso(s) da linguagem; b) averiguar que as práticas linguísticas heterogêneas acompanham a evolução sociocultural de todas as línguas do mundo e que os movimentos em direção à homogeneidade linguística são determinados por fatos sociais, políticos e históricos.

\section{Fundamentação teórica ${ }^{4}$}

A diversidade linguística vivenciada no país é amplamente discutida na área dos estudos da linguagem. Conforme visto em Correa (2009a, 2011b, 2014) a ideologia da 'unidade nacional, essa unidade linguística, foi criada com repetidas ações de violência física e simbólica contra os falantes de outras línguas, haja vista que a política de

\footnotetext{
3 “Racismo linguístico ou ensino pluralista e cidadão?", de Dante Lucchesi (UFBA).

${ }^{4}$ Parte do conteúdo desta fundamentação teórica retoma Correa (2011a).
} 
integração do índio, do negro e do imigrante pressupunha a destruição das línguas e das suas culturas e sua adaptação ao formato luso-brasileiro.

Acrescenta ainda que esta política de integração mudou com a Constituição Federal de 1988. Testemunho dessa mudança tem sido o processo de construção de uma educação escolar indígena diferenciada, bilíngue e intercultural. Entretanto, o Estado não agiu da mesma maneira para com os cidadãos falantes de línguas alóctones ou de imigração.

Por seu turno, Makoni e Meinhof (2006, p. 192) retomam Bloch (2002, p. 24) ao trazer para discussão um ângulo muito importante dessa questão.

A retórica do multilinguismo explica a existência de muitas línguas não como um problema, mas como uma vantagem [...]. Insistir que o multilinguismo é um trunfo é uma posição que não é sensível à condição de pessoas multilíngues pobres. Saber que o multilinguismo constitui uma forma de riqueza cultural não oferece nenhum benefício a tais pessoas. É importante formular modos alternativos de tratar dessas questões se quisermos convencer pessoas leigas da validade de nossos argumentos (BLOCH, 2002, p. 24 apud MAKONI, MEINHOF, 2006, p. 192).

Para estes pesquisadores, uma vez que as línguas são socialmente construídas, precisam ser desconstruídas de tempos em tempos, para que se tornem tão compreensíveis quanto possível, de modo que o padrão se aproxime do uso do estudante.

A alternativa seria fazer com que a consciência sociolinguística se tornasse parte do currículo, de modo a transmitir a ideia de adequação funcional diferenciada dos vários usos. O argumento para tal procedimento não é totalmente diferente daquele que promove uma língua-padrão para o uso institucional em geral, mas reconhece as variedades em outros domínios. A outra alternativa é experimentar, no ensino de línguas, o uso de materiais baseados em textos autênticos de variedades diferentes (MAKONI; MEINHOF, 2006, p. 200).

Tendo em vista o cunho performativo da linguagem, que a faz realizar-se como uma série de atos, a discussão dos elementos que compõem o campo das políticas linguísticas permite compreender melhor a complexa realidade que configura as práticas de linguagem, posto que acrescenta subsídios importantes para ampliar a visão sobre os construtos sociais e culturais que acompanham essas práticas e podem possibilitar maior engajamento com a pluralidade e, assim, envolver experiências com as diferenças.

Esse comprometimento é parte de um processo que leva, de forma inevitável, à discussão sobre a natureza fluida do conceito de língua, sobre os elementos que confluem para a criação dos ambientes linguísticos e as implicações de tais ações para a qualificação do ensino.

O ponto de vista performativo de J. L. Austin (1962), representado no Brasil por vários pesquisadores (SILVA, 2008; PINTO, 2007, 2014; RAJAGOPALAN, 2009, 2014, entre outros), constitui referência fundamental para esta discussão. A escola de pensamento denominada Filosofia da Linguagem Ordinária e, mais especificamente, a configuração inovadora desta corrente, situa-se na função interventora, no uso performativo da linguagem. Trata-se de um movimento filosófico que se desenvolveu 
na Inglaterra no período entre as grandes guerras e que alcançou seu auge no final da década de 1940 ao início da década de 1960.

Austin classificou os enunciados em performativos e constativos. Estes se caracterizam pela propriedade de descrever a realidade exterior e por serem livres da intromissão de qualquer usuário, ou seja, que possam ocorrer por meio da linguagem e destinam-se a avaliar o binômio verdade/falsidade dos enunciados; ao passo que aqueles não cumprem a mesma função e são concebidos como felizes ou infelizes, de acordo com as condições em que são expressos.

Em How to do things with words (1962a), Austin argumenta que uma sentença como "O gato está sobre o capacho", que tem sido analisada como declarativa (ou "constativa", conforme terminologia de Austin) e, portanto, passível de ser considerada verdadeira ou falsa, é de fato uma sentença "performativa", que não pode ser considerada verdadeira ou falsa, mas apenas feliz ou outra coisa qualquer, dependendo das circunstâncias em que foi proferida ("performed"). Daí nasce a ideia de que falar uma língua é realizar ("performing") uma série de atos. Esta ideia seminal inspirou acadêmicos de diversas disciplinas, incluindo linguística, psicologia, antropologia, sociologia, e mesmo campos não correlatos, como a economia (RAJAGOPALAN, 2010, p. 26).

Nessa visada, os ambientes linguísticos são configurados a partir de construtos sociais e artefatos culturais e tais configurações devem uma considerável parte do seu entendimento ao campo das políticas linguísticas e planificação linguística, uma vez que a realidade linguística mostra-se complexa e o conceito de língua camufla a ideia de homogeneidade. Mas, em uma observação mais esmerada, esse conceito apresenta-se fluido por dizer respeito a questões que se configuram performativamente.

Em Rajagopalan (1998), encontra-se que a linguagem é essencial na discussão da pós-modernidade, mas os linguistas não se reconhecem nessa discussão, pois abandonaram as reflexões sobre a linguagem em detrimento da descrição da língua e seus funcionamentos. Ainda em Rajagopalan (2003), esse ponto de vista é reiterado, ao afirmar que o que torna o conceito clássico de língua cada vez mais difícil de se sustentar é que ele abriga não só a ideia de autossuficiência, mas também faz vistas grossas às heterogeneidades que marcam todas as comunidades de fala. Isto é, as diferenças são tratadas como fenômenos contingentes a serem estudados num segundo momento.

No caso da linguística, tudo começa pela definição de linguagem. O que é linguagem? Algo que existe como uma potencialidade, uma capacidade na mente humana? $\mathrm{Ou}$ existe, contrariamente, como algo que está materialmente presente - na qualidade de enteléquia, para usar o termo aristotélico - no dia-a-dia de cada um de nós? Quem tem a posse da linguagem? Um indivíduo concebido idealmente, dotado de atributos que o distingam de seus primos distantes de carne e osso? Ou será que só faz sentido falar da linguagem em relação a uma comunidade de indivíduos, cujas identidades se revelariam atravessadas pelas marcas da rede de relações sociais da qual participam efetiva e inescapavelmente? A habilidade linguística é algo igualmente distribuído entre todos numa comunidade? Ou será que há diferenças entre subgrupos de uma mesma comunidade? Todas as línguas estão em pé de igualdade do ponto de vista funcional? $\mathrm{Ou}$ algumas seriam mais bem-dotadas que outras para desempenhar as mesmas funções? (RAJAGOPALAN, 2003, p. 50) 
Por todas essas razões, propomos discutir o tema considerando as práticas linguísticas usuais em diferentes contextos.

[...] o primeiro grande desafio da linguística para o século XXI é a redefinição de seu objeto, retomando a linguagem como objeto e não o sistema. $\mathrm{E}$, nos modos de funcionamento da linguagem, redefinir a língua, no sentido de produto sempre inacabado desse trabalho, que continua sendo feito (GERALDI, 2003, p. 88).

Em Faraco (2008), encontramos a seguinte reflexão sobre a complexa realidade sociolinguística configurada no Brasil a partir da intensificação do acesso à escola e da urbanização:

Até hoje a sociedade brasileira não foi capaz de entender e assimilar essa realidade. E a escola menos ainda. Não conseguimos desarmar os espíritos frente às características do chamado português popular. Por isso mesmo, não criamos ainda uma pedagogia adequada aos falantes dessas variedades do português, uma pedagogia que lhes permita ao mesmo tempo incorporar a seu repertório o português urbano (a linguagem urbana comum e as práticas da cultura escrita). (FARACO, 2008, p. 189).

O funcionamento estrutural e funcional da língua está relacionado à fixação de regras, à terminologia, é parte do sistema no qual sujeitos agem em conformidade com ações planejadas sobre a língua. Há dois tipos de gestão das situações linguísticas: uma que procede das práticas sociais (gestão in vivo) e outra da intervenção sobre essas práticas (gestão in vitro).

Os instrumentos de planejamento linguístico atuam, portanto, como a tentativa de adaptação e de utilização in vitro de fenômenos que sempre se manifestaram in vivo. E a política linguística vê-se, então, diante, ao mesmo tempo, dos problemas de coerência entre os objetivos do poder e as soluções intuitivas que são frequentemente postas em prática pelo povo, bem como do problema de certo controle democrático.

Por outro lado, há que se ver os problemas de forma, o estatuto da língua e a diferença entre planejamento de status e de corpus (HAUGEN, 1968; FISHMAN, 2006). O planejamento de status está relacionado ao papel da língua, às funções que ela vai exercer, seu status social e suas relações com as outras línguas (como língua nacional, língua oficial, meio de instrução etc.). Por sua vez, o planejamento de corpus diz respeito às intervenções na forma ou variedade da língua que vai ser escolhida como modelo para a sociedade e promovida como tal (criação de um sistema de escrita, neologia, padronização).

Cooper (1989) propôs o planejamento de aquisição como uma terceira etapa do planejamento linguístico. Dessa forma, vão se configurando os ambientes linguísticos. A partir dessa presença ou ausência das línguas sob a forma oral ou escrita na vida cotidiana das pessoas e das práticas sociais, atendendo às necessidades da sociedade, $\mathrm{o}$ planejamento agirá sobre o ambiente, para intervir no peso das línguas na sua presença simbólica. Mais uma vez, a ação in vitro utiliza os meios da ação in vivo, inspira-se nela, mesmo que dela se diferencie ligeiramente.

Entretanto, na hora de transferir essa faculdade da língua para as circunstâncias de sala de aula, a inserção da política linguística é uma aliada e envolve elementos de ordem prioritariamente normativa, conforme enfatiza Rajagopalan (2008, p. 14): 
A questão do planejamento linguístico foi tratada como assunto proibido durante muito tempo, graças à insistência por parte dos linguistas de se afastar de qualquer atividade que soasse ingerência em assuntos linguísticos. Pois, o fato é que política linguística e planejamento linguístico são, sem sombra de dúvida, questões que envolvem interferência proposital no destino de uma língua (ou de várias línguas). São atividades escancaradamente normativas, prescritivas. Daí o motivo pelo qual os linguistas sempre encontraram certa dificuldade em abertamente assumir posturas políticas, posto que o seu grito de guerra - gesto que cabe dentro da política da linguística - sempre foi o de insistir em que suas investigações científicas eram rigorosamente descritivas, jamais prescritivas.

O que é preciso ressaltar é que, na maioria das vezes, ao proceder ao planejamento de status de uma língua, desconsidera-se seu valor cultural e o que esse valor tem para aqueles falantes em termos de constituição de identidade.

Nesse sentido, conforme já dito, as práticas linguísticas trazem na sua configuração elementos que são de ordem multicultural e sociohistórica, os quais definem tais práticas. E entre esses elementos, no contexto escolar, há discussões em torno das práticas pedagógicas que buscam atender as especificidades da norma culta.

Entretanto, conforme salienta Bourdieu (1996, p. 117-118),

Na verdade, sabe-se que a ordem social deve em parte sua permanência à imposição de esquema de classificação que, por se ajustarem às classificações objetivas, acabam produzindo uma forma de reconhecimento desta ordem que implica justamente o desconhecimento da arbitrariedade de seus fundamentos: a correspondência entre as divisões objetivas e os esquemas classificatórios, entre as estruturas objetivas e as estruturas mentais, está na raiz de um tipo de adesão originária à ordem estabelecida.

Por essa razão, é necessário discutir de forma mais intensa e coordenada, nos cursos de Licenciatura em Letras e nos cursos de formação continuada de professores, como se dá o planejamento linguístico, haja vista que muitos não discutem e até desconhecem políticas linguísticas, ou seja, os mecanismos agentes na configuração dos ambientes linguísticos. Dessa maneira, podem-se compreender melhor as origens dessa ordem, de onde vêm seus fundamentos.

Da mesma forma, Zilles (in FARACO, 2008, p. 19), ao fazer referência aos debates e às tarefas das pedagogias da variação linguística, lembra que:

A grande expectativa é de que essa estratégia leve a uma política linguística mais consistente, especialmente no que diz respeito aos modelos de língua prestigiados como norma em nossa sociedade. Será necessário envolver os professores, os alunos e os pais, nas escolas; no contexto mais amplo, devemos envolver os profissionais da área da comunicação, os agentes literários, os editores e profissionais da linguagem em geral. Em especial, é premente a necessidade de trazer para o debate nossos escritores, alguns dos quais têm se pronunciado apresentando concepções desinformadas, conservadoras e preconceituosas sobre as discrepâncias entre o modo como falamos e escrevemos, de um lado, e, de outro, o modo como acreditam que deveríamos falar e escrever, bem ao gosto, lamentavelmente, dos afiliados da norma curta.

Uma discussão que envolva variados segmentos da sociedade, mas principalmente os que trabalham mais diretamente com o tema, tem mais chances de elucidar questões cruciais para que as crenças sobre ensino-aprendizagem de língua 
sejam passíveis de reflexões mais abrangentes e fundamentadas. Entre elas, as que dizem respeito à norma culta.

Nesse sentido, é importante lembrar que, conforme Faraco (2008), o qualificativo culta designa "a norma linguística praticada, em determinadas situações (aquelas que envolvem certo grau de monitoramento), por aqueles grupos sociais que têm estado mais diretamente relacionados com a cultura escrita" (FARACO, 2008, p. 56).

Entretanto, considerando o acesso efetivo à cultura letrada, em especial, a escrita como um bem cultural de poucos,

[...] ela também pode funcionar entre nós como um fator de discriminação social, cultural e econômica. No fundo, ela não perdeu entre nós seu defeito de origem - ou seja, continua recoberta por uma aura elitista que se materializa na norma curta, ou seja, na insistência em se interditar a ocorrência na escrita de fenômenos normais na fala culta (Idem, p. 61).

Dessa forma, as pressões exercidas pelo discurso hegemônico, defensor obstinado do ensino da norma-padrão, definida como homogênea e idealizada, ainda exercem extrema influência. Por essa razão, há que se investir esforços para que se reflita sobre os construtos sociais e artefatos culturais que definem as identidades e que tais configurações devem uma considerável parte do seu entendimento ao campo das políticas linguísticas e planificação linguística, uma vez que a realidade linguística mostra-se complexa e o conceito de língua camufla a ideia de homogeneidade, mas em uma observação mais esmerada apresenta-se fluido por dizer respeito a questões que se configuram performativamente.

Nesse sentido, a visão performativa da linguagem pode contribuir para a desconstrução do conceito de língua, auxiliando a compreensão de que língua é um conjunto de variedades e de que as políticas linguísticas são interventoras nos destinos dessas línguas.

Por fim, a compreensão do papel limitador da norma curta, conforme trazida por Faraco, pode abrir caminhos para a criação de políticas linguísticas e educacionais que levem a maiores esclarecimentos no sentido de desarticular a noção de língua, conforme Pinto (2010).

\section{Apresentação e análise dos dados}

O estudo envolve pesquisa-ação. Acompanhei uma turma de primeiro ano do curso de Licenciatura em Letras durante um ano ${ }^{5}$, de modo que formamos um grupo de pesquisa no $\mathrm{LET}^{6}$. Trata-se de uma pesquisa interventiva ${ }^{7}$, na medida em que há contato

\footnotetext{
5 A proposta é acompanhar os acadêmicos durante o tempo de formação, quatro anos, com o intuito de concluir o estudo durante a formação da turma. Entretanto, por ora, os resultados registram dados relativos ao primeiro ano de estudo.

${ }^{6} \mathrm{O}$ laboratório a que nos referimos denomina-se Laboratório de Estudos do Texto (LET) e foi aprovado na Universidade Estadual de Ponta Grossa/PR pela Resolução CEPE n. ${ }^{\circ}$ 217, de 13 de dezembro de 2007. Trata-se de um Programa de Extensão sob minha coordenação, professora lotada no Departamento de Letras Vernáculas da UEPG e docente permanente do Mestrado em Linguagem, Identidade e Subjetividade. Neste espaço, propomos congregar projetos direcionados para, basicamente, duas
} 
maior entre os participantes e a pesquisadora, acompanhamento das aulas que envolvem leitura e produção de textos na graduação, reuniões de grupo para estudos.

Foram realizados cinco encontros para discussão do tema, além dos estudos em sala de aula. Nestes encontros, os participantes puderam expressar suas visões sobre língua(gem), gramática, escrita, oralidade, norma culta e norma padrão, atrelando essas questões à formação de professores. Esses pontos de vista foram registrados na forma de entrevistas. Selecionei os dados de três participantes, os quais são apresentados abaixo. Os grifos são sempre meus.

\section{Participante 1}

Escolher o Curso de Licenciatura em Letras foi um "nadar contra a corrente", afinal, português nunca foi a minha paixão. Como a maneira que fui "ensinada" a escrever redação não foi uma das melhores, uma das expectativas que criei sobre o curso foi a de aprender a escrever redações. As professoras falavam da estrutura de uma dissertação: introdução, desenvolvimento e conclusão. Ao ver delas bastava a estrutura, sem conter muitos argumentos.

No depoimento da primeira participante, o que se pode observar, de início, é a percepção das dificuldades em relação à língua, que ela chama de "Português", aludindo à disciplina, mas concomitante ou subjacente a essa alusão, às práticas de linguagem propriamente ditas. Ao acrescentar o desejo de escrever com segurança e conhecimento, manifesta a vontade de dominar as normas do escrever de acordo com as normas que prescrevem essa prática linguística e, paralelamente, faz uma autoavaliação bastante negativa acerca da sua competência nessa habilidade.

Por outro lado, a participante destaca o papel das professoras, que valorizavam um aspecto do texto em detrimento dos demais, além de ditarem uma estrutura canônica de composição textual bastante conhecida de todos nós, já exaustivamente discutida em manuais da área, mas nem por isso tratada de maneira mais adequada.

Veja o exemplo de um dos fatos ocorridos: "A professora passou como atividade uma redação de tema "aborto", cinco alunos entregaram (de uma turma de 30). Na outra semana, redação com o tema violência, valendo 1 ponto, metade da turma entregou. Porém, 90\% entregaram de qualquer forma, sem estrutura. Ao perceber isso, a professora começou a avaliar as redações valendo 2 pontos; 1 se estivesse na estrutura e outro pela escrita (erros ortográficos)".

ramificações: a primeira subdivisão acolhe os projetos de pesquisa cujos objetivos estão ligados a preocupações com ensino, de maneira que procura alicerce no diálogo que se estabelece entre pesquisa e procedimentos metodológicos que envolvam atividades relacionadas a ensino; o segundo segmento destina-se a desenvolver trabalhos que contemplam a formação inicial e continuada de professores por meio da criação de espaços para professores em formação, formados e pesquisadores interagirem em grupos de estudos, cursos, minicursos e eventos que propiciem a formação integrada do professor e do pesquisador. A partir de fevereiro de 2010, com o início das atividades letivas do Mestrado em Linguagem, Identidade e Subjetividade, alunos de pós-graduação também passaram a integrar as discussões. No início de 2015, o LET passou a sediar também um Núcleo de Estudos sobre Educação Básica.

${ }^{7}$ Ressalto que um recorte desta proposta de estudo foi apresentado e discutido no minicurso "Reflexões sobre política linguística e ensino de língua", ministrado em parceria com a Professora Letícia Fraga, no $64^{\circ}$ Seminário do GEL. 
Pelo exemplo relatado pela participante, o que se pode depreender é que mediante comandos que não oferecem a menor autonomia para o aluno pensar acerca dos fatores diversos que podem compor um contexto tão vulnerável quanto o que a professora propõe tematizar, o resultado não pode ser diferente: um pouco mais de $10 \%$ dos alunos atendeu ao solicitado.

Com a segunda mudança de estratégia por parte da professora (atribuição de valor para avaliação), houve um progresso em termos quantitativos, entretanto, sem comprometimento com a qualidade do trabalho.

$\mathrm{Na}$ terceira tentativa de mudar a estratégia de avaliação, o que se pode observar é que: a) a avaliação se restringe à materialidade do texto, b) o que se toma por "escrita" é ortografia.

Ou seja, pelo exemplo acima, percebe-se a falha no ensino da escrita, por isso, imaginei que os acadêmicos de Letras aprendem a escrever. Com esses 6 meses de curso percebi não ser bem isso, a maioria já escreve bem e as professoras exigem certo nível dos acadêmicos. Entretanto, é correto exigir esse nível, pois a maioria dos alunos tem o hábito de leitura, o que facilita na escrita. Essa é outra falha na educação e uma das expectativas que criei sobre o curso e que se concretizou.

Para concluir, a participante 1 consegue discernir o que é escrita como prática inserida em um âmbito maior, que é língua. Embora não consiga verbalizar objetivamente o que a inquieta, não se intimida e manifesta as incoerências das práticas pedagógicas de escrita e leitura. Mesmo com poucos meses de curso, percebe-se que a maioria dos alunos construiu suas práticas escolares e linguísticas de maneira mais adequada, as quais configuram algumas diferenças entre os colegas. Essas diferenças, se discutidas e bem compreendidas, podem ser meios de aprimorar ainda mais o trabalho do grupo nas aulas de graduação.

Participante 2 (grifo nosso)

Ao ser aprovado no vestibular da Universidade Estadual de Ponta Grossa (UEPG), no ano de 2011, já tinha a expectativa de que seria muito útil conhecer os conceitos corretos para o uso da língua portuguesa e espanhola, poder dominar a norma padrão, utilizar com facilidade as regras da escrita, da oralidade e da leitura, essas técnicas seriam úteis e necessárias em vários momentos da minha vida, no ambiente profissional, familiar, social, pessoal, me ajudariam principalmente no desenvolvimento da minha capacidade de elaborar projetos, realizar pesquisas e atuar em programas de ensino. Durante este primeiro semestre, em que estive participando das aulas na UEPG, pude reforçar essas expectativas iniciais, surpreendeu-me o método de ensino, os textos debatidos, os temas indicados e todas as disciplinas do curso.

O participante 2 apresenta uma visão bem recorrente de língua e linguagem. Primeiramente fala de língua (portuguesa e espanhola), demonstrando que sua noção de língua se aplica da mesma maneira para ambas as línguas. Em um segundo momento, observa-se que ele inicia sua fala valorizando sobremaneira a norma padrão, as regras da escrita padrão e o valor cultural dessa modalidade de uso em diversos ambientes sociais, tais como os acadêmicos e os escolares. 
Eis então que, mesmo reforçando as expectativas, ele se manifesta surpreso, conforme os dados que se seguem, nos quais ele fala das disciplinas do primeiro ano do Curso (grifo nosso):

A disciplina de linguística me fez derrubar vários paradigmas pessoais, ela conseguiu debater a distinção entre língua e gramática, essa percepção ampliou a minha capacidade de conviver e aceitar as diferenças, aceitar outras formas de linguagem, respeitar a diversidade cultural, valorizar as características regionais, aceitar o outro sem me espantar com o uso distinto da língua, decorrente de características geográficas, culturais, de meio, experiências pessoais, entonação e outras particularidades, destacando a capacidade criativa e o uso correto da gramática na produção de textos.

O participante veio então conhecer que a língua (seja portuguesa ou estrangeira) não é um todo homogêneo, que é preciso considerar as práticas linguísticas advindas dos mais diferentes espaços culturais, os quais são configurados pelas diferenças e que a norma culta é uma entre as muitas normas que devem ser conhecidas e respeitadas por todos.

O ensino de gramática está sendo pulverizado entre as disciplinas, por exemplo, na disciplina de latim, observamos a origem dos termos, regras e a análise da estrutura das frases. Para a língua estrangeira, o destaque é para a capacidade e criatividade do educador, usando métodos de memorização, expressão, leitura, pesquisas socioculturais dos países que usam a língua espanhola, suas características regionais, pesquisas e apresentação de temas pelos próprios alunos, tudo isso combinado com um excelente senso de humor e criatividade, divertindo a turma com observações pontuais que ensinam e divertem, está sendo uma ótima experiência para mim, o respeito e a forma de chamar a atenção e a responsabilidade do aluno, para mim, são um exemplo de profissionalismo e didática.

E assim ele prossegue, descrevendo o trabalho com a língua $\mathrm{e}$ os desdobramentos desse trabalho em outras disciplinas, com práticas interdisciplinares que levam à discussão sobre questões socioculturais atreladas às de linguagem.

A disciplina de língua e texto conseguiu me esclarecer muitas dúvidas, de início já me conscientizou das minhas limitações e do que seria necessário para o meu desenvolvimento, a maneira como é apresentado o conteúdo aos alunos tende a destacar a importância do desenvolvimento da capacidade criativa, da análise crítica, do emprego correto dos conceitos gramaticais, da coesão e coerência, excelente o estudo e a percepção da importância do desenvolvimento constante desta capacidade.

Nesse excerto, ele já demonstra ter conquistado mais autonomia para percorrer o universo da escrita em suas especificidades: as prescritivas e as subjetivas. Sem conhecer ainda os mecanismos que definem as práticas hegemônicas de escrita, ele vislumbra esse universo. Especial atenção para os termos "análise crítica" e "desenvolvimento constante desta capacidade".

As disciplinas de Fundamentos da Educação e a Psicologia desenvolvem as capacidades de reflexão sobre a profissão do educador, o histórico e as características de cada período de estudo, as técnicas, os métodos e a evolução dos estudos. A disciplina de Prática reforça os conceitos, complementa o desenvolvimento, desenvolve a capacidade de desenvolver projetos e pesquisas relacionadas com o curso, também possibilita a 
experiência de participar como observador em ambientes reais, ampliando a nossa percepção do que vem pela frente, ser um professor.

Por fim, o participante 2 lembra que será professor. Embora pareça óbvio, nem todos os que procuram um curso de Licenciatura comprometem-se com a formação para essa função social, portanto, é sempre bom lembrar.

\section{Participante 3}

O curso de Letras pode passar um pouco longe de suas expectativas. Ao escolher o curso que iremos prestar vestibular fazemos uma série de escolhas e medimos nossas aptidões. Não basta gostar de Português, deve haver uma paixão pela escrita, leitura e por tudo que a linguagem possa nos oferecer. E disso só temos consciência ao ingressar no curso porque é quando nos abrem os olhos para este imenso universo da Linguagem. Há, talvez, alunos de Letras que não sabem ou não gostam de escrever, e isto, apesar de confrontante, é muito comum. Acredito que estes mesmos alunos terminarão este curso com a opinião totalmente mudada. [...]

A participante 3 tem, a princípio, um olhar muito lúcido sobre a escolha que fez. Embora não omita que as expectativas não foram as que previu, pois foram ampliadas para o "imenso universo que é a linguagem", lembra das dificuldades que alguns têm em escrever e ler. Ao mesmo tempo, crê que elas serão superadas.

Um dos equívocos é pensar que se aprenderá gramática na Universidade ou que o aluno de Letras deve funcionar como um dicionário humano. A gramática foi aprendida no Ensino Médio e até agora (primeiro ano) ela não nos foi sequer apresentada. Mas acredito que ainda iremos nos deparar com ela, porém como algo mais aprofundado. [...]

Com relação ao sempre desejado domínio da gramática - que a participante não especifica, mas sabemos que está se referindo à normativa - de forma implícita, ela já sugere que essa gramática perpassa o imaginário das pessoas e aos poucos verá que essa discussão sobre as normas que regem uma língua não se restringe à memorização de regras e sim às causas que levam à criação e manutenção dessas regras e, principalmente, às consequências delas.

A partir do exposto, podemos observar, em um primeiro momento, que os participantes têm conhecimento dos ambientes que perpassam o imaginário da maioria das pessoas, ou seja, de que existe uma língua e que essa língua representa a unidade histórica, política e social da nação. Com o andamento das aulas, eles vão tomando conhecimento dos diversos fatores que envolvem as práticas linguísticas e socioculturais diversas.

Segundo. Inicialmente, ele vê a língua que representa uma nação. Essa língua é homogênea, os falantes são monolíngues e a norma padrão é "a língua". No decorrer das discussões, essa visão vai se ampliando e os participantes iniciam um processo de reconstrução de conhecimentos sobre linguagem.

Terceiro. As implicações mais polêmicas das discussões são aquelas que reafirmam os preconceitos, os quais vêm manifestados linguisticamente, mas não demoram a se mostrar extensivas a outras categorias ou práticas do comportamento humano, tais como opção sexual, classe social, entre outras. 
Quarto. Desde o princípio, os participantes reconhecem a escrita como um instrumento que garante a estabilidade da norma padrão, ou seja, da visão homogênea de língua. Após algumas leituras e várias discussões, vão internalizando os usos da norma culta e o que os diferencia da norma padrão. Essa compreensão advém de muitas discussões e exemplos e exige muitas leituras específicas sobre os temas.

O fato é que os estudantes percebem, conforme vimos em Rajagopalan (2003), que o conceito clássico de língua está cada vez mais difícil de se sustentar, uma vez que ele abriga não só a ideia de autossuficiência, mas também faz vistas grossas às heterogeneidades que marcam todas as comunidades de fala. Ou seja, as diferenças são tratadas como fenômenos contingentes a serem estudados num segundo momento.

Outro ponto inquestionável é que discutir políticas linguísticas com os professores participantes os auxilia a compreender os mecanismos que definem os usos da linguagem e as relações que se estabelecem entre as noções de língua e de cultura, de modo que eles vêem que as práticas linguísticas heterogêneas acompanham a evolução sociocultural de todas as línguas do mundo e que os movimentos em direção à homogeneidade linguística são determinados por fatos sociais, políticos e históricos, mantendo assim a premissa de que o Brasil é plurilíngue e multicultural, ou seja, a ideologia da unidade nacional, essa unidade linguística foi criada com repetidas ações de violência física e simbólica contra os falantes de outras línguas, haja vista que a política de integração do índio, do negro e do imigrante pressupunha a destruição das línguas e das suas culturas e sua adaptação ao formato luso-brasileiro (OLIVEIRA, 2000).

Dessa maneira, o processo de formação dos professores da área de Letras, do ponto de vista curricular, adquire contornos interdisciplinares e o perfil identitário desses participantes (professores pesquisadores) vai se delineando sobre bases mais sólidas e mais abrangentes.

\section{Sobre os resultados}

O conhecimento dos processos históricos, socioculturais, linguísticos e de políticas linguísticas que envolvem a constituição das línguas e das práticas de linguagem pode propiciar maior autonomia para propor estudos, pesquisas, discussões e encaminhamentos pedagógicos, seja sob a égide de uma posição científica, seja de uma proposta intervencionista no campo social e educacional.

Os resultados deste estudo, até o momento, apontam que a maioria dos professores em formação reconhece as diferenças linguísticas, socioculturais e históricas, entretanto não se sente preparada para discutir tais diferenças em sala de aula e propor encaminhamentos.

Ao apresentar os dados coletados nas investigações com os professores em formação, mostro aspectos que mudaram no primeiro ano da formação desses professores e que ajudarão a compor um diagnóstico configurado mais objetivamente. Pude constatar que a discussão sobre políticas linguísticas e situações sociolinguisticamente complexas proporciona mais maturidade e autonomia em relação à capacidade de discutir conhecimentos sobre língua(gem). Até o momento, posso afirmar que se observa uma maturidade teórica. Quanto à prática, somente quando esses graduandos começam a ir para a escola é que poderemos constatar. Por ora, há maior 
impacto nas discussões acerca do discurso praticado em relação ao ensino de língua, tanto no âmbito das instâncias educacionais e acadêmicas quanto das instâncias públicas.

Por fim, é possível ver que os professores participantes da pesquisa reconhecem que "toda a gama de variedades deve ser encarada com seriedade, sem discriminação" (JABUR, 2014, p. 44) que, ao se tornarem professores pesquisadores, auxiliam a dar continuidade à tarefa de rever essas questões cruciais para um ensino de língua mais qualificado, ou seja, mais adequado às necessidades dos usuários da língua(gem).

\section{REFERÊNCIAS}

AUSTIN, J. L. How to do things with words. Oxford: Clarendon Press, 1962.

BOURDIEU, P. A economia das trocas linguísticas: o que falar quer dizer. 2. ed. São Paulo: Editora da Universidade de São Paulo, 1996.

BRASIL. Secretaria de Educação Fundamental. Parâmetros Curriculares Nacionais: terceiro e quarto ciclos do ensino fundamental: língua portuguesa. Secretaria de Educação Fundamental. Brasília: MEC/SEF, 1998.

BRITTO, L. P. L. Educação linguística escolar: para além das obviedades. In: CORREA, D. A.; SALEH, P. B. de O. (Org.). Estudos da linguagem e currículo de Letras: diálogos (im)possíveis. Ponta Grossa: EDUEPG, 2008.

CALVET, L-J. Sociolinguística: uma introdução crítica. São Paulo: Parábola Editorial, 2004.

As políticas linguísticas. São Paulo: Parábola Editorial, IPOL, 2007.

COOPER, R. L. Language planning and social change. Cambridge: Cambridge University Press, 1989.

CORREA, D. A. Política linguística e ensino de língua. Calidoscópio, v. 7, n. 1, p. 6975, jan./abr. 2009a.

A escrita em uma abordagem integracionista: um estudo introdutório. In:

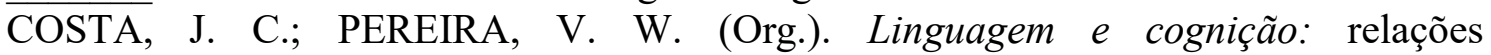
interdisciplinares. Porto Alegre: EdiPUCRS, 2009b. p. 275-289. 672, 2011a.

Aspects of writing and identity. Language Sciences (Oxford), v. 33, p. 667-

Políticas linguísticas e ensino: um convite à discussão. In: BATTISTI, E.; COLLISCHONN, G. (Org.). Lingua e linguagens: perspectivas de investigação. v. 1. Pelotas: EDUCAT - Editora da Universidade Católica de Pelotas, 2011b. p. 105-124.

Práticas linguísticas e ensino de língua: variáveis políticas. In: CORREA, D.

A. (Org.). Política linguística e ensino de língua. v. 1. Campinas: Pontes, 2014. p. 2137.

DIONNE, H. A pesquisa-ação para o desenvolvimento local. Tradução de Michel Thiollent. Brasília: Líber Livro Editora, 2007. 
FARACO, C. A. Por uma pedagogia da variação linguística. In: CORREA, D. A. (Org.). A relevância social da Linguística: linguagem, teoria e ensino. São Paulo: Parábola Editorial; Ponta Grossa, UEPG, 2007. p. 21-50. 2008. Norma culta brasileira: desatando alguns nós. São Paulo: Parábola Editorial,

FISHMAN, J. A. Do NOT leave your language alone: the hidden status agendas within corpus planning in language policy. Mahwah: Lawrence Erlbaum Associate Publishers, 2006.

FLICK, U. Introdução à pesquisa qualitativa. 3. ed. Porto Alegre: Artmed, 2009.

GATTI, B. Estudos quantitativos em educação. Educação e Pesquisa, São Paulo, v. 30, n. $1, \quad$ p. 11-30, jan./abr. 2004. Disponível em: $<$ http://www.scielo.br/pdf/ep/v30n1/a02v30n1.pdf>. Acesso em: 07 mai. 2016.

GERALDI, J. W. João Wanderley Geraldi. In: XAVIER, A. C.; CORTEZ, S. (Org.). Conversas com linguistas. Virtudes e controvérsias. São Paulo: Parábola Editorial, 2003.

Rethinking writing. London: Athlone. 2000.

HAUGEN, E. Language planning in Modern Norway. In: FISHMAN, J. (Ed.). Readings in the sociology of languages. Paris: Mouton de Gruyter, 1968. p. 673-687.

JABUR, E. N. A. Ensino de língua na escola pública. In: CORREA, D. A. (Org.). Política linguística e ensino de língua. v. 1. Campinas: Pontes, 2014. p. 37-44.

MAKONI, S.; MEINHOF, U. Linguística aplicada na África: desconstruindo a noção de língua. In: MOITA LOPES, L. P. da. (Org.). Por uma linguística aplicada (in)disciplinar. São Paulo: Parábola Editorial, 2006.

OLIVEIRA, G. M. A virada político-linguística e a relevância social da linguística e dos linguistas. In: CORREA, D. A. (Org.). A relevância social da Linguística: linguagem, teoria e ensino. São Paulo: Parábola Editorial; Ponta Grossa: UEPG, 2007. p. 79-93.

. Línguas como Patrimônio Imaterial (06/01/2009). Disponível em: $\overline{<\mathrm{http}: / / w w w . i p o l . o r g . b r />}$. Acesso em: 26 mar. 2009.

OLIVEIRA, G. M. de. Brasileiro fala português: Monolinguismo e Preconceito Linguístico. In: MOURA, H. M.; SILVA, F. L. (Org.). O direito à fala: a questão do preconceito linguístico. Florianópolis: Editora Insular, 2000. p. 83-84.

(Org.). Declaração universal dos direitos linguísticos. Campinas: Mercado de Letras, Associação de Leitura do Brasil (ALB); Florianópolis: IPOL, 2003.

PAIVA, M. C. A variável gênero/sexo. In: MOLLICA, M. C.; LUIZA, B. M. (Org.). Introdução à sociolinguística: o tratamento da variação. São Paulo: Contexto, 2004.

PINTO, J. P. Conexões teóricas entre performatividade, corpo e identidades. DELTA. Documentação de Estudos em Lingüística Teórica e Aplicada, v. 23, p. 1-26, 2007.

. Da língua-objeto à práxis linguística: desarticulações e rearticulações contra hegemônicas. Linguagem em Foco, v. 2, p. 69-83, 2011. 
. Hegemonias, contradições e desafios em discursos sobre língua no Brasil. In: CORREA, D. A. (Org.). Política Linguística e ensino de língua. Campinas: Pontes Editores, 2014. p. 59-72.

RAMOS, H. Por uma Vida Melhor. Programa Nacional do Livro Didático para a Educação de Jovens e Adultos, 2011.

RAJAGOPALAN, K. 'A ideologia de homogeneização: reflexões concernentes à questão da heterogeneidade na linguística'. Revista Letras, v. 14, n. 14, p. 21-37, 1997.

Política linguística e a política da linguística. In: SIMÕES, D.; HENRIQUES, C. C. (Org.). Língua Portuguesa, Educação \& Mudança. Rio de Janeiro: Ed. Europa, 2008. p. 11-22. 2009.

. "A norma linguística do ponto de vista da política linguística". Manuscrito,

O professor de línguas e a suma importância do seu entrosamento na política linguística do seu país. In: CORREA, D. A. (Org.). Política Linguística e Ensino de Língua. v. 1. Campinas: Pontes, 2014. p. 73-82.

SILVA, D. N. A questão da identidade em perspectiva pragmática. Revista Brasileira de Linguística Aplicada, v. 8, p. 13-33, 2008.

SILVA, D. N.; FERREIRA, D. M. M.; ALENCAR, C. N. (Org.). Nova Pragmática: modos de fazer. São Paulo: Cortez, 2014.

SAUSSURE, F. Curso de linguística geral. São Paulo, Cultrix/EDUSP, 1969.

TELLES, J. A. “É pesquisa, é? Ah, não quero, não, bem!” Sobre pesquisa acadêmica e sua relação com a prática do professor de línguas. Linguagem \& Ensino, v. 5, n. 2, p. 91-116, 2002. Disponível em: <http://rle.ucpel.tche.br/php/edicoes/v5n2/f_joao.pdf>. Acesso em: 18 mar. 2016.

THIOLlent, M. Metodologia de pesquisa-ação. 17. ed. São Paulo: Cortez, 2009.

TRIVIÑOS, A. N. S. Introdução à pesquisa em ciências sociais: a pesquisa qualitativa em educação. Tradução de Joice Elias Costa. São Paulo: Atlas, 2009.

Recebido em: 03/10/2016

Aprovado em: 29/11/2016 